LAWRENCE LIVERMORE NAT IO N A L LABORATORY
Experimental and Computational Study of Nonpremixed Ignition of Dimethyl Ether in Counterflow

X.L. Zheng, T.F. Lu, C.K. Law, C.K. Westbrook

December 22, 2003

30th International Symposium on Combustion Chicago, IL, United States

July 25, 2003 through July 30, 2003 
This document was prepared as an account of work sponsored by an agency of the United States Government. Neither the United States Government nor the University of California nor any of their employees, makes any warranty, express or implied, or assumes any legal liability or responsibility for the accuracy, completeness, or usefulness of any information, apparatus, product, or process disclosed, or represents that its use would not infringe privately owned rights. Reference herein to any specific commercial product, process, or service by trade name, trademark, manufacturer, or otherwise, does not necessarily constitute or imply its endorsement, recommendation, or favoring by the United States Government or the University of California. The views and opinions of authors expressed herein do not necessarily state or reflect those of the United States Government or the University of California, and shall not be used for advertising or product endorsement purposes. 


\title{
Experimental and Computational Study of \\ Nonpremixed Ignition of Dimethyl Ether in Counterflow
}

\author{
X. L. Zheng, T. F. Lu, and C. K. Law \\ Department of Mechanical and Aerospace Engineering \\ Princeton University, Princeton, NJ 08540 \\ C. K. Westbrook \\ Lawrence Livermore National Laboratory, Livermore, CA94550
}

Corresponding Author:

Professor C.K. Law

Department of Mechanical and Aerospace Engineering

Princeton University, Princeton, NJ 08544

Tel: (609) 258-5271

Fax: (609) 258-6233

E-mail: cklaw@princeton.edu

Subject:

Reaction Kinetics

The total word count (exclusive of title page, abstract) is 5985:

Main text: MS Word XP, word count $=4479$ words

Figures: (7 figures $)_{-}\left(7 \mathrm{~mm}+0.84 \_67 \mathrm{~mm}\right) \_(2.2 \text { words } / \mathrm{mm})+146$ words $=1121$ words Reference: $(20$ references +2$) \_(2.3 \text { lines/reference })_{-}(7.6$ words/line $)=385$ words

Submitted for oral presentation at the Thirtieth Symposium (International) on Combustion and for publication in the Proceedings of the Combustion Institute. 


\title{
Experimental and Computational Study of
}

\section{Nonpremixed Ignition of Dimethyl Ether in Counterflow}

\author{
X. L. Zheng, T.F. Lu, and C. K. Law \\ Department of Mechanical and Aerospace Engineering \\ Princeton University, Princeton, NJ 08540 \\ C. K. Westbrook \\ Lawrence Livermore National Laboratory, Livermore, CA94550
}

\begin{abstract}
The ignition temperature of nitrogen-diluted dimethyl ether (DME) by heated air in counterflow was experimentally determined for DME concentration from 5.9 to $30 \%$, system pressure from 1.5 to 3.0 atmospheres, and pressure-weighted strain rate from 110 to $170 / \mathrm{s}$. These experimental data were compared with two mechanisms that were respectively available in 1998 and 2003, with the latter being a substantially updated version of the former. The comparison showed that while the 1998-mechanism uniformly over-predicted the ignition temperature, the 2003-mechanism yielded surprisingly close agreement for all experimental data. Sensitivity analysis for the near-ignition state based on both mechanisms identified the deficiencies of the 1998-mechanism, particularly the specifics of the low-temperature cool flame chemistry in effecting ignition at higher temperatures, as the fuel stream is being progressively heated from its cold boundary to the high-temperature ignition region around the hot-stream boundary. The 2003mechanism, consisting of 79 species and 398 elementary reactions, was then systematically simplified by using the directed relation graph method to a skeletal mechanism of 49 species and 251 elementary reactions, which in turn was further simplified by using computational singular perturbation method and quasi-steady-state species assumption to a reduced mechanism consisting of 33 species and 28 lumped reactions. It was demonstrated that both the skeletal and reduced mechanisms mimicked the performance of the detailed mechanism with high accuracy.
\end{abstract}

Keywords: dimethyl ether, ignition, reduced mechanism 


\section{Introduction}

Dimethyl Ether (DME), $\mathrm{CH}_{3} \mathrm{OCH}_{3}$, is an attractive alternate fuel and fuel additive for diesel engines. It is the simplest linear ether, has no carbon-carbon bond, and has the lowest possible carbon-to-hydrogen ratio. It has a high cetane number in the range of 5560 , and it does not tend to form particulates. The combination of high cetane number and a low boiling point of $-25^{\circ} \mathrm{C}$ facilitate mixing, ignition, and cold start [1].

There have been a number of kinetic studies on the pyrolysis and oxidation of DME [2-8]. Dagaut et al. [2] obtained jet-stirred reactor (JSR) results in the high temperature range of $800 \sim 1300 \mathrm{~K}$. Pfahl and co-workers [3] measured the ignition delay times of stoichiometric mixtures behind reflected shocks at pressures of 13 and 40 bar and temperatures of $650 \sim 1300 \mathrm{~K}$. These data were used by Curran et al. [4] to develop a detailed mechanism. Dagaut et al. [5] subsequently extended their JSR experiments to the lower temperature range of 550 1100K, and developed a reaction mechanism with 55 species and 331 reactions. Fischer et al. [6] and Curran et al. [7] studied both high temperature pyrolysis and oxidation, and low temperature oxidation in a variablepressure flow reactor (VPFR). Formic acid, which was not included in the previous mechanism [4], was found to be a major intermediate of DME oxidation at low temperatures. A mechanism of 78 species and 336 reactions, incorporating the chemistry leading to formic acid formation, was subsequently proposed. Most recently, Curran [8] updated the DME mechanism from references [4-7] as part of a larger new propane reaction mechanism, reflecting improved thermochemistry and some newly re-evaluated reaction rates. The DME submechanism of Curran [8] was used in the calculations below 
as the 2003-mechanism. Interested readers are directed to Prof. Curran for copies of the reaction mechanism.

These studies were based on experimental data from homogeneous systems. There are very limited experimental data for inhomogeneous systems. For high temperature oxidation, Daly et al. [9] measured the laminar flame speeds of DME/air in a spherical bomb, while Kaiser et al. [10] performed experimental and modeling studies of premixed atmospheric-pressure DME/air flames. However, there are no experimental data for ignition in diffusive systems suitable for the scrutiny of low- to intermediatetemperature chemistry. Consequently, there are three primary objectives of the present investigation. First, we have acquired high fidelity experimental data from nonpremixed ignition in a counterflow geometry, in which the strain rate provides a well-defined characteristic flow time. Second, we compare these data with existing DME mechanisms, and subsequently identify the crucial reactions that control the ignition process.

Through such a comparison the 2003-mechanism was found to be capable to accurately simulate the experimental data acquired over diverse ignition conditions. Consequently, our third objective is to reduce this detailed mechanism to smaller ones using rigorously developed mathematical theories and numerical algorithms, with minimal compromise of fidelity and comprehensiveness, such that it can be more readily applied to complex simulations which are heavily CPU time-demanding.

\section{Experimental and Computational Specifications}

Detailed descriptions of the experimental equipment and technique are given in

Ref. 11. Briefly, the counterflow ignition apparatus consists of two opposing $20 \mathrm{~mm}$ i.d. 
quartz tubes which are separated by one tube diameter and housed in a variable pressure chamber. The cold DME $/ \mathrm{N}_{2}$ was issued from the bottom tube, flowing against the downward-directed air stream, which was electrically heated by a silicon carbide heater regulated by a proportional-integral-derivative temperature controller (J-Kem Model 250). The flow rates were adjusted by mass flow controllers (Teledyne Hastings) such that the stagnation surface was halfway between the quartz tubes. Ignition was achieved by gradually increasing the air stream temperature. The velocity field was measured by a two-component Laser Doppler Velocimetry (LDV) system with frequency shifting (Dantec), and the strain rate was determined as the axial velocity gradient on the oxidizer side of the stagnation plane. The ignition temperatures were measured by a K-type thermocouple with a bead diameter of about $180 \mu \mathrm{m}$, with correction for radiative/convective heat transfer [11]. This yielded an absolute error of $\pm 15 \mathrm{~K}$ for the ignition temperature. The repeatability of the experimental data was $\pm 2 \sim 5 \mathrm{~K}$.

Ignition calculations were performed using the flame continuation method developed by Nishioka et al. [12], with detailed transport and chemistry $[13,14]$. In conduction the simulation, we have used the mechanism of Curran et al. [4], hereafter referred as the 1998-mechanism, and its very recently updated version, 2003-mechanism, also by Curran [8]. In the simulation the ignition S-curve was constructed by determining the steady state solution for different hot boundary temperatures assuming potential flow, and the peak $\mathrm{CH}_{3}$ radical mole fraction was used to monitor the system response. The ignition temperature was defined as that of the hot boundary at the ignition turning point of the resulting S-curve. It is noted that previous ignition studies [11] have demonstrated that since ignition is mainly governed by the local velocity gradient immediately 
upstream of the mixing layer on the oxidizer side, the use of the simpler potential flow formulation adequately describes the ignition characteristics.

\section{Results and Discussion}

\subsection{Ignition temperatures of DME}

Figure 1 plots the ignition temperature as a function of DME mole fraction in nitrogen at 3atm and a pressure weighted strain rate of $150 \mathrm{~s}^{-1}[11,15]$. It is seen that the ignition temperature monotonically decreases with increasing fuel concentration in the fuel jet. This is physically reasonable, and is also in agreement with the behavior of hydrogen and hydrocarbon fuels investigated previously $[11,16,17]$. Furthermore, such dependence becomes stronger for lower fuel concentration. Finally, while the 1998-mechanism substantially over-predicts the ignition temperature, the 2003-mechanism agrees very closely with the experimental data.

The effect of pressure on the ignition temperature of DME is shown in Fig. 2. The maximum pressure investigated experimentally is $3 \mathrm{~atm}$, being limited by the DME vapor pressure (about 5.6atm) at room temperature. Results show that the ignition temperature decreases monotonically with increasing pressure, which is again physically reasonable, and that, similar to the comparison in Fig. 1, the 2003-mechanism yields close agreement with the experimental data while the 1998-mechanism over-predicts the ignition temperature. We shall therefore use only the 2003-mechanism in the following calculations.

Studies on paraffinic hydrocarbons ignition $[16,17]$ have shown that the ignition temperature increases with increasing strain rates as a consequence of the reduced 
residence time for reactants. For the same reason, the DME ignition temperature should exhibit the same dependence on the strain rate. Figure 3 shows the experimental ignition temperature as a function of pressure-weighted strain rate for $30 \% \mathrm{DME}$ in $\mathrm{N}_{2}$ under three different pressures, while Fig. 4 shows the dependence at 3atm for three DME concentrations. It is seen that, for both cases, the agreement between experiment and calculation is again very close. Moreover, the ignition temperature increases with increasing strain rate as expected, and the effects of strain rate, pressure and fuel concentration on ignition do not seem to be strongly coupled. As illustrated in Fig. 3 and 4, varying pressure from $2 \mathrm{~atm}$ to $3 \mathrm{~atm}$, or the DME concentration from $5.9 \%$ to $30 \%$, mainly shifts the ignition temperature curves downward, without affecting the qualitative trend.

\subsection{Comparison of the1998- and 2003-mechanisms}

The two DME reaction mechanisms used in the present model calculations are derived from the same primary author $[4,8]$, and it is very clear from the results shown in Figs. 1 and 2 that computed results using the newer mechanism are considerably better than using the older version, and the differences are especially pronounced at lower temperatures. Furthermore, the excellent agreement between experimental and computed results using the newer mechanism in Figs. 1-4 suggests that it is generally more accurate than its predecessor. Accordingly, we have used the 2003-mechanism for most of the remaining calculations in this work. At the same time, we have made a careful analysis of the changes made in the mechanism from the initial to the final version in order to provide a form of sensitivity analysis of the mechanism to better understand the 
influences of the different parts of the mechanism on DME ignition. We have supplemented this analysis with further, more formal sensitivity analysis as well.

The overall reaction path analysis described by Curran et al. [4] applies quite well to the present results. DME is consumed primarily by $\mathrm{H}$ atom abstraction by radicals, primarily $\mathrm{OH}$ and $\mathrm{H}$. However, at the somewhat elevated pressures and intermediate temperatures in this study, abstraction of $\mathrm{H}$ atoms from $\mathrm{DME}$ by $\mathrm{HO}_{2}$ and $\mathrm{CH}_{3} \mathrm{O}_{2}$ through

$$
\begin{aligned}
& \mathrm{CH}_{3} \mathrm{OCH}_{3}+\mathrm{HO}_{2}=\mathrm{CH}_{3} \mathrm{OCH}_{2}+\mathrm{H}_{2} \mathrm{O}_{2} \\
& \mathrm{CH}_{3} \mathrm{OCH}_{3}+\mathrm{CH}_{3} \mathrm{O}_{2}=\mathrm{CH}_{3} \mathrm{OCH}_{2}+\mathrm{CH}_{3} \mathrm{O}_{2} \mathrm{H}
\end{aligned}
$$

is also quite important. Curran et al. [7] pointed out that these abstraction reactions accelerate DME ignition because their products, $\mathrm{H}_{2} \mathrm{O}_{2}$ and $\mathrm{CH}_{3} \mathrm{O}_{2} \mathrm{H}$, readily decompose at temperatures about $1000 \mathrm{~K}$ to produce two radicals each,

$$
\begin{aligned}
& \mathrm{H}_{2} \mathrm{O}_{2}+\mathrm{M}=\mathrm{OH}+\mathrm{OH}+\mathrm{M} \\
& \mathrm{CH}_{3} \mathrm{O}_{2} \mathrm{H}=\mathrm{CH}_{3} \mathrm{O}+\mathrm{OH}
\end{aligned}
$$

providing chain branching from the consumption of $\mathrm{HO}_{2}$ and $\mathrm{CH}_{3} \mathrm{O}_{2}$. This effect is in contrast to the major alternative pathways for their consumption, such as

$$
\mathrm{HO}_{2}+\mathrm{HO}_{2}=\mathrm{H}_{2} \mathrm{O}_{2}+\mathrm{O}_{2}
$$

which, when followed by Reaction 3 above, is a sequence that results in two $\mathrm{OH}$ radicals from two $\mathrm{HO}_{2}$ radicals for chain propagation. A major difference between the older DME mechanism and the present one is that the rates of Reactions 1 and 2 above are 1.68 times faster in the present mechanism. Since the levels of $\mathrm{HO}_{2}$ and $\mathrm{CH}_{3} \mathrm{O}_{2}$ decrease rapidly as temperature increases above $1000-1100 \mathrm{~K}$, these reaction paths are most important at lower temperatures and are responsible for preferentially accelerating the lower temperature portions of Figs. 1 and 2 where the two mechanisms disagree most. 
The $\mathrm{CH}_{3} \mathrm{OCH}_{2}$ radicals begin to decompose at temperatures above about $1000 \mathrm{~K}$ in this work, while at lower temperatures they add to molecular oxygen

$$
\mathrm{CH}_{3} \mathrm{OCH}_{2}+\mathrm{O}_{2}=\mathrm{CH}_{3} \mathrm{OCH}_{2} \mathrm{O}_{2}
$$

This reaction is fast in both the forward and reverse directions in the present conditions, and the equilibrium is strongly temperature dependent, favoring $\mathrm{CH}_{3} \mathrm{OCH}_{2} \mathrm{O}_{2}$ until the temperature reaches about $800 \mathrm{~K}$. At temperatures below this level, a sequence of reactions produces considerable reactivity through

$$
\begin{aligned}
& \mathrm{CH}_{3} \mathrm{OCH}_{2} \mathrm{O}_{2}=\mathrm{CH}_{2} \mathrm{OCH}_{2} \mathrm{O}_{2} \mathrm{H} \\
& \mathrm{CH}_{2} \mathrm{OCH}_{2} \mathrm{O}_{2} \mathrm{H}+\mathrm{O}_{2}=\mathrm{O}_{2} \mathrm{CH}_{2} \mathrm{OCH}_{2} \mathrm{O}_{2} \mathrm{H} \\
& \mathrm{O}_{2} \mathrm{CH}_{2} \mathrm{OCH}_{2} \mathrm{O}_{2} \mathrm{H}=\mathrm{HO}_{2} \mathrm{CH}_{2} \mathrm{OCHO}+\mathrm{OH} \\
& \mathrm{HO}_{2} \mathrm{CH}_{2} \mathrm{OCHO}=\mathrm{OCH}_{2} \mathrm{OCHO}+\mathrm{OH}
\end{aligned}
$$

These "cool flame" reactions, made possible because Reaction 6 has produced the first species in the sequence, provides two $\mathrm{OH}$ radicals and another complex radical in the form of $\mathrm{OCH}_{2} \mathrm{OCHO}$, and is therefore a quite strong chain branching sequence. Most of the $\mathrm{OH}$ radicals then react with DME and make even more chain branching and reactivity. If the heat produced by these reactions could be removed rapidly enough, this sequence would completely consume the fuel via an isothermal chain reaction.

As in cool flames for many other fuels, temperature increase interferes with this low-temperature chain branching reaction sequence. Competing reactions with greater temperature sensitivity compete with reactions $\mathrm{R} 6$ through $\mathrm{R} 8$ and disrupt their progress. For example, $\beta$-scission decomposition of $\mathrm{CH}_{2} \mathrm{OCH}_{2} \mathrm{O}_{2} \mathrm{H}$ through

$$
\mathrm{CH}_{2} \mathrm{OCH}_{2} \mathrm{O}_{2} \mathrm{H}=\mathrm{CH}_{2} \mathrm{O}+\mathrm{CH}_{2} \mathrm{O}+\mathrm{OH}
$$


competes with reaction $\mathrm{R} 8$ but produces only one $\mathrm{OH}$ radical, so this alternative pathway provides only chain propagation and, in comparison with Reactions 8-10, retards ignition. The decomposition Reaction 11 is exothermic and has an activation energy of about $80 \mathrm{~kJ} / \mathrm{mol}$ while the addition Reaction 8 has no activation energy barrier, so increasing temperature will steadily increase the contribution of the decomposition pathway and reduce the overall reactivity.

Similarly, the equilibria for the two $\mathrm{O}_{2}$ addition Reactions 6 and 8 are strongly temperature dependent, and as temperature increases above about $750 \mathrm{~K}$, the equilibrium in both reactions shifts towards dissociation back to $\mathrm{O}_{2}$ and the radical. This shift very effectively shuts off the low temperature branching pathways and is the source of the "negative temperature coefficient" (NTC) regime for this system. In this regard we note that another important change between the 1998- and 2003-mechanisms was a recalculation of the thermochemistry of many of the species, which changed the equilibrium constants of many of these addition reactions.

It is important to remember in this experimental configuration that the fuel is initially at low temperature as it enters the flame region and is heated steadily by the opposing flow of heated air. For a given sample of fuel, its reactivity will be determined by the time-varying local concentration of oxygen, the time-dependent temperature, and the reaction pathways that are accessible under those conditions. For example, a sample that ignites at 1000K in Fig. 1 or 2 will have experienced some time at every intervening temperature and some amount of reaction will have affected its composition. Diffusion of species from other regions in the flame will also affect the species concentrations at every location. With increasing strain rate, reactants will spend less time in each 
temperature and composition interval, so reaction pathways at each stage will have a proportionally smaller effect. Fuel that is consumed early in the flame at lower temperatures by the cool flame kinetic processes therefore reduces the amount of time required at higher temperatures to complete fuel consumption and reach ignition. This is very much analogous to the influence of the same cool flame kinetics on engine knock in spark-ignition engines; fuel consumption that occurs at lower temperatures makes it easier to reach ignition in the time available from the experimental configuration. As noted earlier, the strain rate sets a limit to the time available for the fuel to ignite, and increasing the strain rate reduces that time available, which then means that the mixture requires a higher temperature to compensate for that smaller residence time to ignite.

Similarly, the reactivity and the corresponding amount of fuel consumption that occurs in the low temperature, cool flame regime increase as the fuel concentration increases. This is true because the $\mathrm{CH}_{3} \mathrm{OCH}_{2}$ radical, produced directly from the DME fuel, is the initial step in the low temperature Reaction 6 pathway that leads to low temperature reactivity, so richer mixtures react more rapidly than leaner mixtures in this temperature regime. Therefore the richer reactive mixture requires less residence time at a given temperature (or equivalently, less temperature at a given residence time or strain rate) to complete the process of fuel consumption as the fuel concentration increases, and it therefore ignites at lower temperatures as shown in Fig. 1.

Figure 5 shows the computed ignition S-curves using the 1998- and the 2003mechanism, for situations which showed the greatest differences between the two mechanisms, with $30 \% \mathrm{DME}$ in $\mathrm{N}_{2}, 3 \mathrm{~atm}$, and a strain rate of $150 \mathrm{~s}^{-1}$. It is seen that there is a dramatic difference between the two mechanisms at about $640 \mathrm{~K}$, which is in the NTC 
region. The 2003-mechanism has a significantly higher reactivity there, and exhibits a turning point rather than the inflection point that is associated with the 1998-mechanism results. Figure 5 therefore provides a good indication of the major differences between the two mechanisms, which can be summarized by pointing out that the newer mechanism provides a much more detailed and accurate description of the lower temperature kinetics of these mixtures than does the older 1998-mechanism. This is due to several important changes in reaction rates that increase the importance of the lower temperature regime, as well as changes in thermochemistry that affect the equilibrium constants and therefore reverse reaction rates of key reactions in the low temperature regime. All of these modifications were the result of careful and thoughtful incremental changes in theory by Curran, and the benefits of that attention are evident in the present model predictions and the agreement with our experimental results. It should be noted that none of the present experimental results were available to Curran for his mechanism refinements, and the present experiments are therefore a powerful confirmation of those refinements. We should also point out that most of these DME mechanism refinements were already present in the mechanisms of references 6 and 7.

We carried out two detailed sensitivity analyses to help understand the features of the reaction mechanisms. Two locations at which to carry out these sensitivity analyses were selected, using the S-curve shown in Figure 5. One examined the region close to the ignition temperatures with $30 \% \mathrm{DME}$ in $\mathrm{N}_{2}$, 3atm and the strain rate $\mathrm{k}$ of $150 \mathrm{~s}^{-1}$, using values of $\mathrm{T}_{\mathrm{ign}}$ of $1039 \mathrm{~K}$ for the 1998 -mechanism and $942 \mathrm{~K}$ for the 2003 -mechanism. The sensitivity coefficients are defined as $-\partial \ln \mathrm{T}_{\mathrm{ign}} / \partial \ln \mathrm{A}_{\mathrm{i}}$, where $\mathrm{T}_{\mathrm{ign}}$ is the ignition temperature and $\mathrm{A}_{\mathrm{i}}$ is the pre-exponential factor for the ith reaction rate expression. The 
computed sensitivity coefficients are plotted in Figure 6. A positive value means that increasing the rate coefficient accelerates ignition, and vice versa. The values are normalized by the largest value at ignition from both mechanisms. The second sensitivity analysis examined conditions in the negative temperature coefficient region around $640 \mathrm{~K}$; due to space limitations, we will not discuss these results, which are generally consistent with those near the ignition point.

Overall, the 1998-mechanism shows much less sensitivity to the low temperature oxidation submechanism, which is consistent with the significant differences between the S-curves in Fig. 5 in this region. The results for the 2003-mechanism show that, even though the ignition temperature has a fairly high value of $942 \mathrm{~K}$, the majority of the sensitivity come from the low temperature kinetics. This indicates immediately that the fuel consumed in the low temperature regime makes it possible for the mixture to ignite at a lower temperature than would be the case in the absence of this low temperature reactivity. The 1998-mechanism is in some ways a valuable comparison since, as seen in Fig. 5, it produces considerably less low temperature reactivity and therefore does not ignite until a temperature of $1039 \mathrm{~K}$, about $100 \mathrm{~K}$ higher than the flame with the newer reaction mechanism.

In Fig. 6, most of the large positive and negative sensitivity coefficients can be understood quite easily in view of the discussions above. The largest positive and the largest negative values are for the two reactions competing for $\mathrm{CH}_{2} \mathrm{OCH}_{2} \mathrm{O}_{2} \mathrm{H}$; when it adds to $\mathrm{O}_{2}$, the chain branching low temperature sequence is fully engaged, and when it decomposes to formaldehyde and $\mathrm{OH}$, the chain branching is disabled. Several of the most sensitive reactions are converting $\mathrm{HO}_{2}$ and $\mathrm{CH}_{3} \mathrm{O}_{2}$ into $\mathrm{OH}+\mathrm{OH}$ and $\mathrm{CH}_{3} \mathrm{O}+\mathrm{OH}$ via 
$\mathrm{H}$ atom abstraction reactions with DME (Reactions 1 and 2) and $\mathrm{CH}_{2} \mathrm{O}$, followed by Reactions 3 and 4. Some of the major negative sensitivities involve reactions of $\mathrm{HO}_{2}$ that compete with the branching sequence by not permitting the $\mathrm{HO}_{2}$ to be converted to $\mathrm{H}_{2} \mathrm{O}_{2}$. Another interesting competition is for $\mathrm{CH}_{3} \mathrm{OCH}_{2}$; like $\mathrm{CH}_{2} \mathrm{OCH}_{2} \mathrm{O}_{2} \mathrm{H}$, when $\mathrm{CH}_{3} \mathrm{OCH}_{2}$ decomposes thermally, it retards ignition, and when it adds to $\mathrm{O}_{2}$, it accelerates ignition.

Overall, the excellent agreement between experimentally determined ignition temperatures, including absolute temperature values as well as parametric trends, and results computed using the newer 2003-DME mechanism all indicate that the new mechanism is an unusually precise analytical tool for the analysis of these nonpremixed systems. In addition to the large-scale results, there are some fine-structured phenomena that the new mechanism reveals, particularly the low temperature reactivity summarized in the sensitivity analysis as well as in the S-curves in Fig. 5. With all of these features nicely reproduced in the new mechanism, the next challenge is to be able to provide all of this wealth of detail in a greatly reduced form suitable for inclusion in complex fluid dynamical models of practical combustion, which is the subject of the next section.

\section{Skeletal and reduced mechanisms}

\subsection{Mechanism Reduction using DRG and CSP}

In general, mechanism reduction can be conducted at two levels of detail. At the first level, unimportant species and thereby the associated unimportant reactions are identified, based on some rational criteria, and discarded from the detailed mechanism, yielding a so-called skeletal mechanism. At the second level, quasi-steadiness and partial 
equilibrium assumptions are respectively imposed on certain species and reactions of the skeletal mechanism, hence yielding the final, reduced mechanism of an even smaller size.

Various mathematical theories and computational algorithms have been developed for both levels of reduction. For the present study we shall adopt the directed relation graph (DRG) method [19] for skeletal reduction, and the computational singular perturbation (CSP) method [20] to obtain the final reduced mechanism. Briefly, the DRG method is capable to abstract the couplings among the species, and to identify the strongly coupled species groups. The strongly coupled species which are isolated from the mechanism kernel can thus be eliminated in groups. The skeletal mechanism obtained with DRG method has errors bounded by a user specified small value of $\varepsilon$. To obtain a skeletal mechanism with errors bounded by $\varepsilon$ over a sufficiently wide range of parameters such as pressure, temperature, equivalence ratio, and residence time, a group of points in the parametric space can be sampled from typical applications such as the homogeneous systems involving perfectly stirred reactor (PSR) and auto-ignition. The use of the PSR is expected to capture the high-temperature chemistry relevant for burning and extinction, while auto-ignition should describe low- through moderately-hightemperature ignition chemistry. Given a sufficiently wide range of pressure, equivalence ratio, and initial temperature, the sampled data points should cover most of the typical conditions under which the mechanism is to be applied.

In CSP, the time scales of independent modes are summed to an indicator weighed by sufficiently large radical pointers, the reciprocal of which can be defined as the time scale of the species. A critical time scale, say the auto-ignition time for ignition phenomena, is selected to normalize the time scales of species, such that the time scale of 
major species controlling the overall reaction rate of the system is normalized to unity. Species are considered to be QSS if their normalized time scales are smaller than a specified critical value, $\alpha$.

\subsection{Skeletal and Reduced Mechanism for DME Ignition}

Applying the DRG method to the updated mechanism for DME, which consists of 79 species and 398 elementary reactions, it was found that there exist jumps in the number of species at certain values of $\varepsilon$. These jumps are due to the elimination of strongly coupled species groups. The species within such groups therefore can not be separated by specifying different threshold values. In the present study, we selected the criterion $\varepsilon=$ 0.1 , and obtained a skeletal mechanism consisting of 49 species. The species constituting this skeletal mechanism are: $\mathrm{H}, \mathrm{H}_{2}, \mathrm{O}, \mathrm{O}_{2}, \mathrm{OH}, \mathrm{H}_{2} \mathrm{O}, \mathrm{N}_{2}, \mathrm{HO}_{2}, \mathrm{H}_{2} \mathrm{O}_{2}, \mathrm{AR}, \mathrm{CO}, \mathrm{CO}_{2}$, $\mathrm{CH}_{2} \mathrm{O}, \mathrm{HCO}, \mathrm{HO}_{2} \mathrm{CHO}, \mathrm{O}_{2} \mathrm{CHO}, \mathrm{HOCHO}, \mathrm{OCHO}, \mathrm{HOCH}_{2} \mathrm{O}, \mathrm{CH}_{3} \mathrm{OH}, \mathrm{CH}_{2} \mathrm{OH}, \mathrm{CH}_{3} \mathrm{O}$, $\mathrm{CH}_{3} \mathrm{O}_{2} \mathrm{H}, \mathrm{CH}_{3} \mathrm{O}_{2}, \mathrm{CH}_{4}, \mathrm{CH}_{3}, \mathrm{CH}_{2}, \mathrm{CH}_{2}[\mathrm{~S}], \mathrm{CH}, \mathrm{C}_{2} \mathrm{H}_{6}, \mathrm{C}_{2} \mathrm{H}_{5}, \mathrm{C}_{2} \mathrm{H}_{4}, \mathrm{C}_{2} \mathrm{H}_{3}, \mathrm{C}_{2} \mathrm{H}_{2}, \mathrm{CH}_{2} \mathrm{CO}$, $\mathrm{HCCO}, \quad \mathrm{CH}_{3} \mathrm{OCH}_{3}, \quad \mathrm{CH}_{3} \mathrm{OCH}_{2}, \quad \mathrm{CH}_{3} \mathrm{OCH}_{2} \mathrm{O}_{2}, \quad \mathrm{CH}_{2} \mathrm{OCH}_{2} \mathrm{O}_{2} \mathrm{H}, \quad \mathrm{CH}_{3} \mathrm{OCH}_{2} \mathrm{O}_{2} \mathrm{H}$, $\mathrm{CH}_{3} \mathrm{OCH}_{2} \mathrm{O}, \quad \mathrm{O}_{2} \mathrm{CH}_{2} \mathrm{OCH}_{2} \mathrm{O}_{2} \mathrm{H}, \quad \mathrm{HO}_{2} \mathrm{CH}_{2} \mathrm{OCHO}, \mathrm{OCH}_{2} \mathrm{OCHO}, \mathrm{HOCH}_{2} \mathrm{OCO}$, $\mathrm{CH}_{3} \mathrm{OCHO}, \mathrm{CH}_{3} \mathrm{OCO}, \mathrm{CH}_{2} \mathrm{OCHO}$. By eliminating all elementary reactions in the detailed mechanism which has any reactants or products not included in the above set of species, 251 elementary reactions were retained for the skeletal mechanism.

The 49-species skeletal mechanism developed above was further reduced by using CSP to identify the QSS species. By again using PSR and auto-ignition as the data sources, the time scales for each species were calculated for each data point, with their characteristic time scales being those of the extinction and ignition times respectively. The minimum normalized time scale of each species was taken as its characteristic time 
scale because it describes approximately its worst case characteristic time. A species is assumed to be a QSS species if its worst case normalized time scale is shorter than the specified threshold value, $\alpha$. In the present study we selected $\alpha$ to be around 0.01 , which is comparable to the hydrogen kernel species such as $\mathrm{O}$ and $\mathrm{H}$. However, to retain the comprehensiveness and capability of predicting hydrogen enriched applications, the radical $\mathrm{O}$ and $\mathrm{H}$ were not included in QSS species set. This yielded a reduced mechanism consisting of 26 lump steps and 31 species including $\mathrm{N}_{2}$ and Ar. We call this 26-step mechanism, which assumes the following species in quasi steady state: $\mathrm{HCO}, \mathrm{HOCH}_{2} \mathrm{O}$, $\mathrm{CH}_{2} \mathrm{OH}, \mathrm{CH}_{3} \mathrm{O}, \mathrm{CH}_{2}, \mathrm{CH}_{2}[\mathrm{~S}], \mathrm{CH}, \mathrm{C}_{2} \mathrm{H}_{5}, \mathrm{C}_{2} \mathrm{H}_{3}, \mathrm{CH}_{3} \mathrm{OCH}_{2}, \mathrm{CH}_{3} \mathrm{OCH}_{2} \mathrm{O}_{2}, \mathrm{CH}_{2} \mathrm{OCH}_{2} \mathrm{O}_{2} \mathrm{H}$, $\mathrm{CH}_{3} \mathrm{OCH}_{2} \mathrm{O}, \mathrm{O}_{2} \mathrm{CH}_{2} \mathrm{OCH}_{2} \mathrm{O}_{2} \mathrm{H}, \mathrm{OCH}_{2} \mathrm{OCHO}, \mathrm{CH}_{3} \mathrm{OCO}$.

We have further found that $\mathrm{CH}_{3} \mathrm{OCH}_{2}$ and $\mathrm{CH}_{3} \mathrm{CH}_{2} \mathrm{O}_{2}$ are moderately important species in that $\mathrm{CH}_{3} \mathrm{OCH}_{2}$ and $\mathrm{CH}_{3} \mathrm{OCH}_{2} \mathrm{O}_{2}$ control the most important pathway of fuel consumption. Hence by releasing these two species from being QSS, we have a 28-step reduced mechanism that consists of 28 lumped steps and 33 species.

To demonstrate the accuracy of the derived skeletal and reduced mechanisms, Fig. 7 shows the calculated ignition temperature of counterflow ignition at $3 \mathrm{~atm}$ and various DME mole fractions. The skeletal mechanism agrees excellently with the detailed mechanism while the 26-step reduced mechanism slightly differs from the detailed one. However, the 28-step reduced mechanism again achieves extremely close agreement with the detailed mechanism. This state of close agreement was found for all concentration, temperature, and pressure parametric ranges investigated, including predictions of the laminar flame speeds. The validity of the reduced mechanism is therefore established. 


\section{Concluding Remarks}

In the present investigation we have successfully acquired data of high quality on the ignition temperature of nitrogen-diluted DME by counterflowing heated air over extensive ranges in the DME concentration, system pressure, and flow strain rate. These data not only are of practical utility, but they are also useful in the partial validation and development of kinetic mechanisms. With the latter objective in mind, we have demonstrated that the recent, 2003-mechanism of Curran is [8] a significant improvement over its 1998 version [4], providing very close agreement with the present experimental data. By comparing results obtained by using both mechanisms, we have also identified the important roles of the low temperature kinetics in achieving the improvement. The evolutionary nature of the ignition process as the cold fuel steam approaches the hot oxidizer stream is recognized as an integral aspect of the ignition process, particularly the influence of the cool flame chemistry in generating radicals in the colder part of the flow that are used in effecting ignition further downstream near the hot boundary. The utility of the present counterflow ignition experiment, which probes a narrow range of 950 1250K where many practical ignition phenomena occur [20], is also noted.

As an additional contribution, we have also systematically derived a skeletal mechanism with 49 species and 251 elementary reactions, and a reduced mechanism with 33 species and 28 steps. Both mechanism preserve the accuracy and comprehensiveness of the detailed mechanism, and are more amenable for implementation in computations involving complex flows. 


\section{Acknowledgements}

The authors wish to thank Professor Henry Curran of the National University of Ireland, Galway, Ireland for use of his latest DME reaction mechanism. This work at Princeton University was supported by the Army Research Office under the technical monitoring of

Dr. D. Mann and by the Air Force Office of Scientific Research under the technical monitoring of Dr. Julian M. Tishkoff. The work at the Lawrence Livermore National Laboratory was carried out under the auspices of the U.S. Department of Energy under Contract No. W-7405-ENG-48, and was supported by the DOE Office of Transportation Technologies, Gurpreet Singh and John Garbak, program managers. 


\section{References}

1. P.C. Meurer and T.H. Fleisch, Proc. Conf. Program Int. Congress Engine and the Environment, Graz, Austria, August 24-25, 1995.

2. P. Dagaut, J.C. Boettner, and M. Cathonnet, Proc. Combust. Inst. 26 (1996) 627-632.

3. U. Pfahl, K. Fieweger and G. Adomeit, Proc. Combust. Inst. 26 (1996) 781-789.

4. H.J. Curran, W.J. Pitz, C.K. Westbrook, P. Dagaut, J.C. Boettner and M. Cathonnet, Int J Chem Kinet 30 (1998) 229-241.

5. P. Dagaut, C. Daly, J.M. Simmie and M. Cathonnet, Proc. Combust. Inst. 27 (1998) 361-369.

6. S.L. Fischer, F.L. Dryer and H.J. Curran, Int J Chem Kinet 32 (2000) 713-740.

7. H.J. Curran, S.L. Fischer and F.L. Dryer, Int J Chem Kinet 32 (2000) 741-759.

8. H.J. Curran, unpublished proceedings of the European Combustion Meeting, 2003.

9. C.A. Daly, J.M. Simmie, J. Wurmel, N. Djebaili and C. Paillard, Combust. Flame 125 (4) (2001) 1329-1340.

10. E.W. Kaiser, T.J. Wallington, M.D. Hurley, J. Platz, H.J. Curran, W.J. Pitz and C.K. Westbrook, J Phy Chem A 104 (35) (2000) 8194-8206.

11. C.G. Fotache, T.G. Kreutz, D.L. Zhu and C.K. Law, Combust. Sci. Technol. 109 (1-6) (1995) 373-394.

12. M. Nishioka, C.K. Law and T. Takeno, Combust. Flame 104 (3) (1996) 328-342.

13. R.J. Kee, F.M. Rupley and J.A. Miller, Report No. SAND 89-8009B, Sandia National Laboratories, 1989.

14. R.J. Kee, J. Warnatz and J.A. Miller, Report No. SAND 83-8209, Sandia National Laboratories, 1983. 
15. T.G. Kreutz and C.K. Law, Combust. Flame 104 (1-2) (1996)157-175.

16. C.G. Fotache, H. Wang and C.K. Law, Combust. Flame 117 (4) (1999) 777-794.

17.J.D. Blouch, C.J. Sung, C.G. Fotache and C.K. Law, Proc. Combust. Inst. 27 (1998)1221-1228.

18. T.F. Lu and C.K. Law, Submitted to $30^{\text {th }}$ Intl. Combustion Symposium.

19. T.F. Lu, Y. Ju, and C.K. Law, Combust. Flame 126 (1-2) (2001) 1445-1455.

20. C.K. Westbrook, Proc. Combust. Inst. 28 (2000)1563-1577. 


\section{Figure Captains}

Figure 1. Effects of fuel mole fraction on ignition temperature.

Figure 2. Effects of pressure on ignition temperature.

Figure 3. Ignition temperatures of $30 \% \mathrm{DME}$ in $\mathrm{N}_{2}$ as a function of pressureweighted strain rate under three different pressures. Experiments shown as symbols and calculations (2003-mechanism) as lines.

Figure 4. Ignition temperatures versus pressure-weighted strain rate for different DME mole fractions in $\mathrm{N}_{2}$ at $3 \mathrm{~atm}$. Experiments shown as symbols and calculations (2003-mechanism) as lines.

Figure 5. Calculated S-curves for 30\% DME in $\mathrm{N}_{2}$ mixture with $150 \mathrm{~s}^{-1}$ strain rate and 3atm, using both mechanisms.

Figure 6. S-curve sensitivity results at ignition for $30 \% \mathrm{DME}$ in $\mathrm{N}_{2}$ mixture at a strain rate of $150 \mathrm{~s}^{-1}$ and $3 \mathrm{~atm}$, using both mechanisms.

Figure 7. Comparison of the computed results using detailed, 49-species skeletal, 26step and 28-step reduced mechanisms for the counterflow ignition temperatures with various DME mole fractions. 


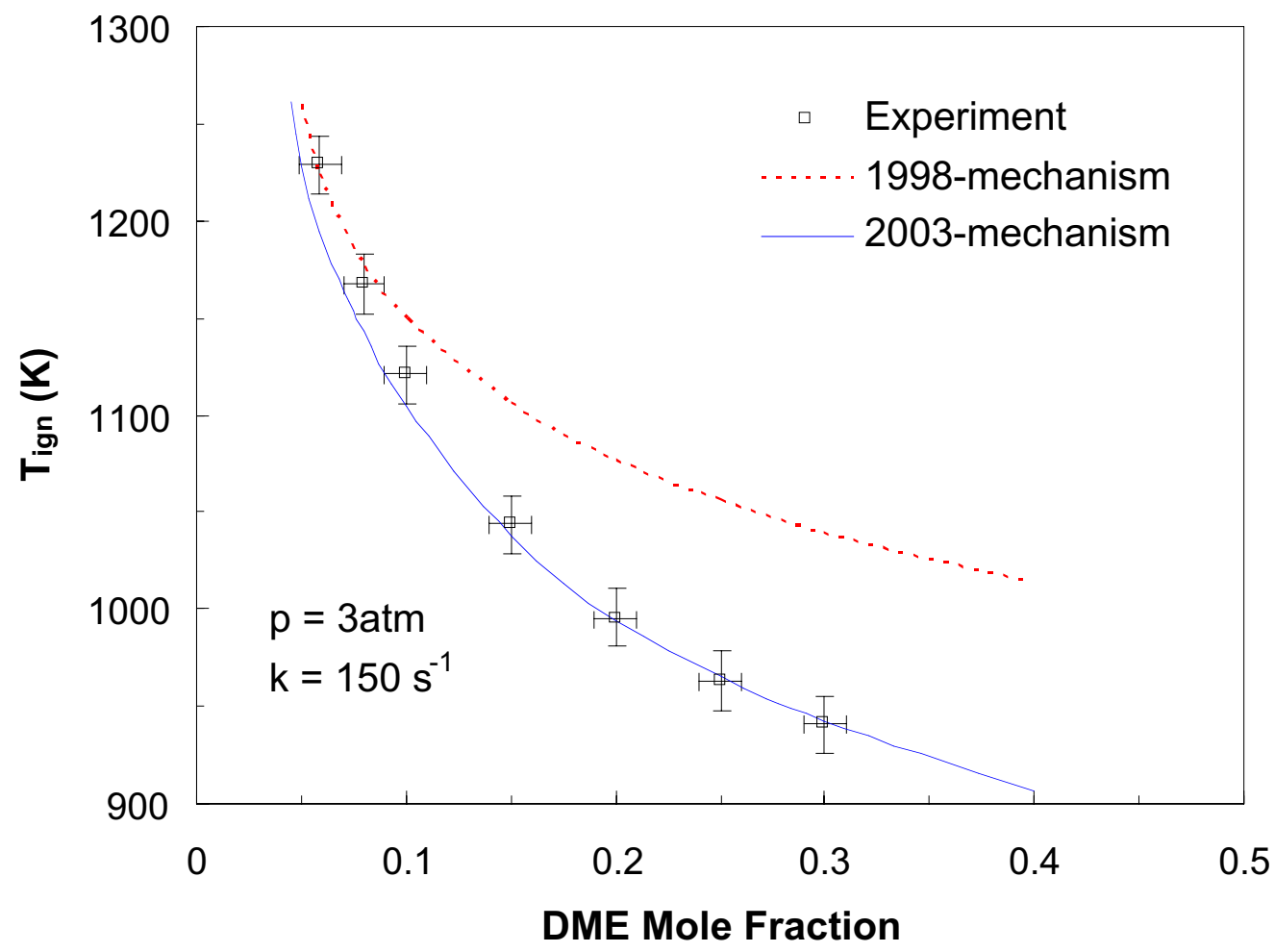

Figure 1 


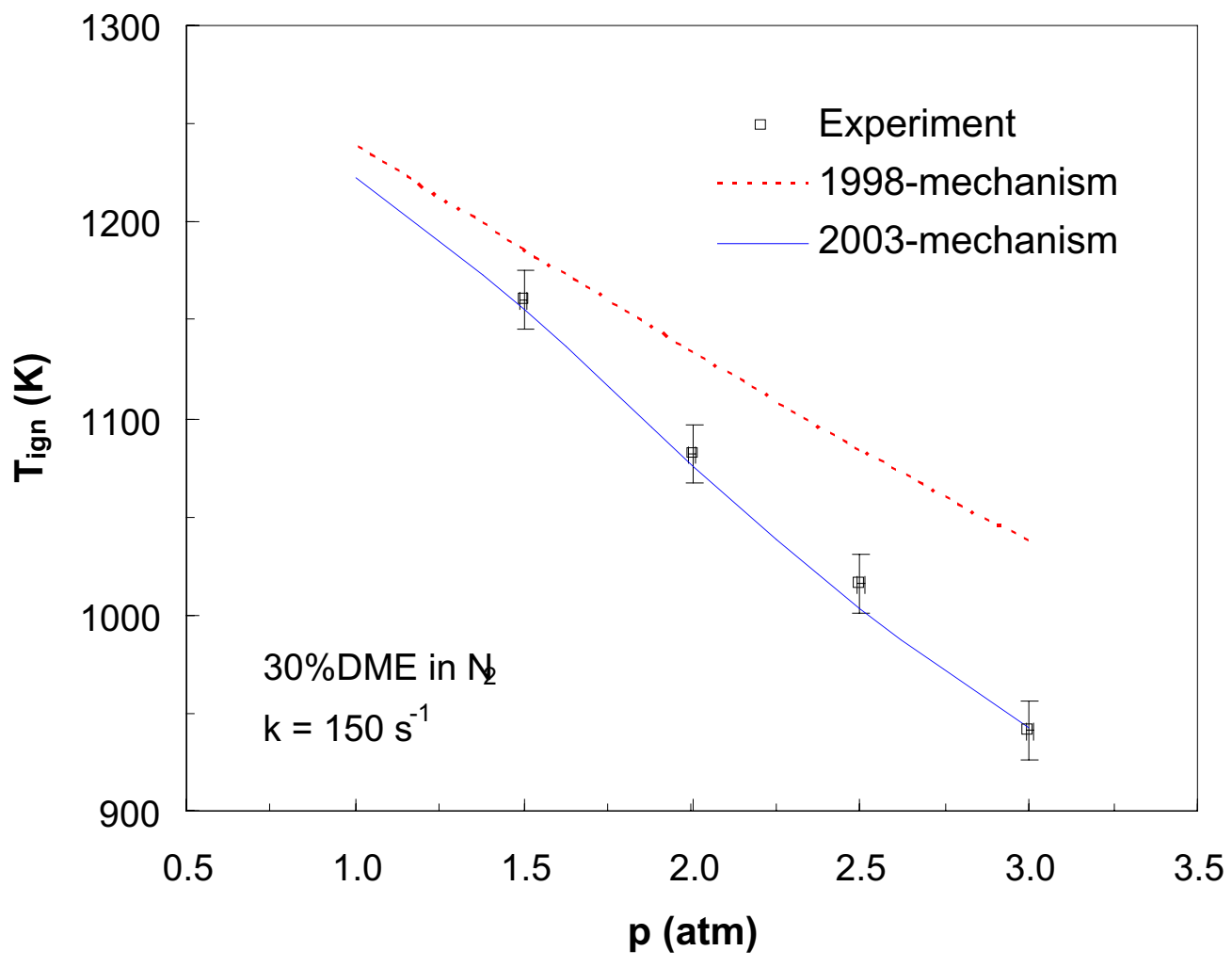

Figure 2 


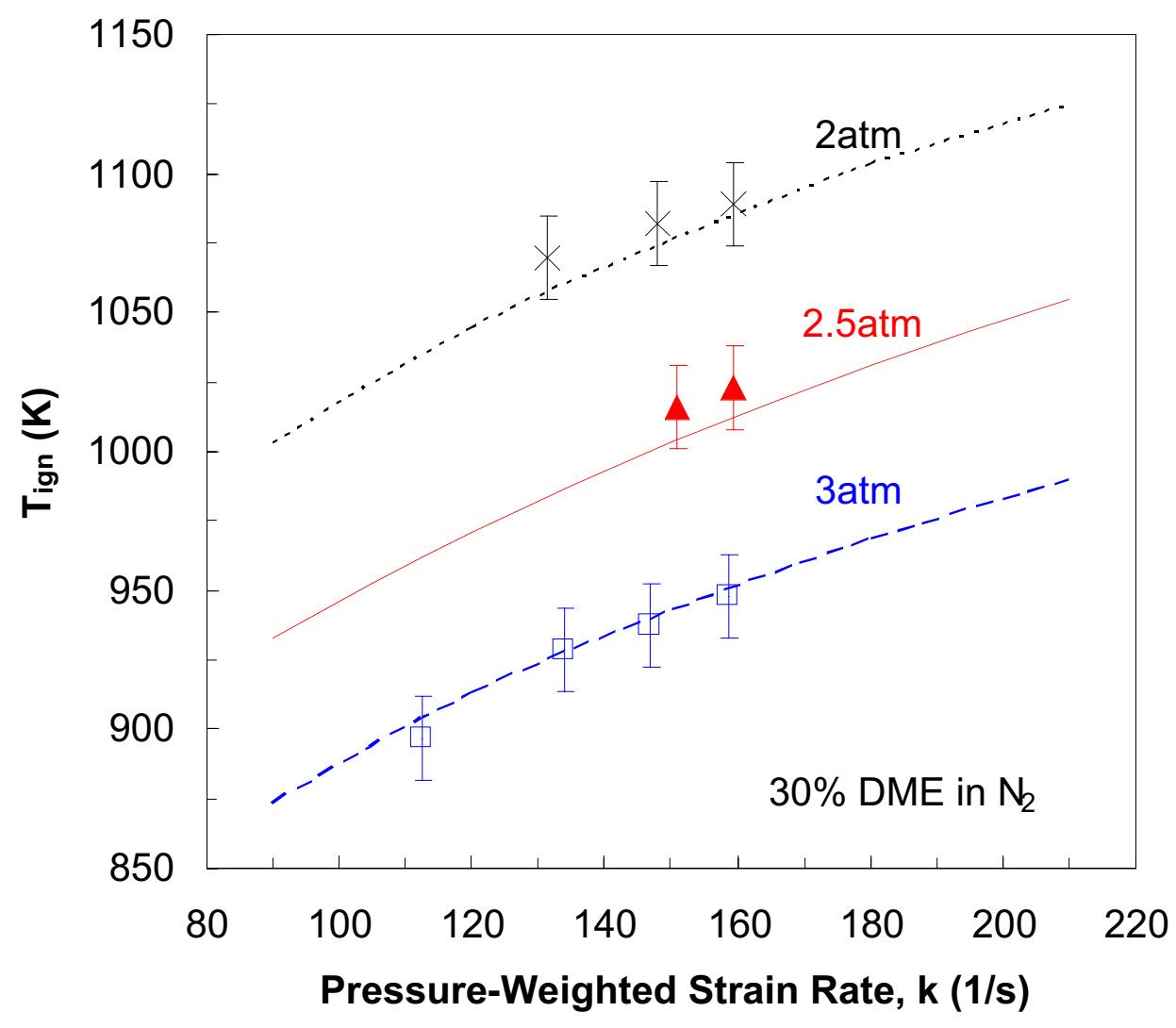

Figure 3 


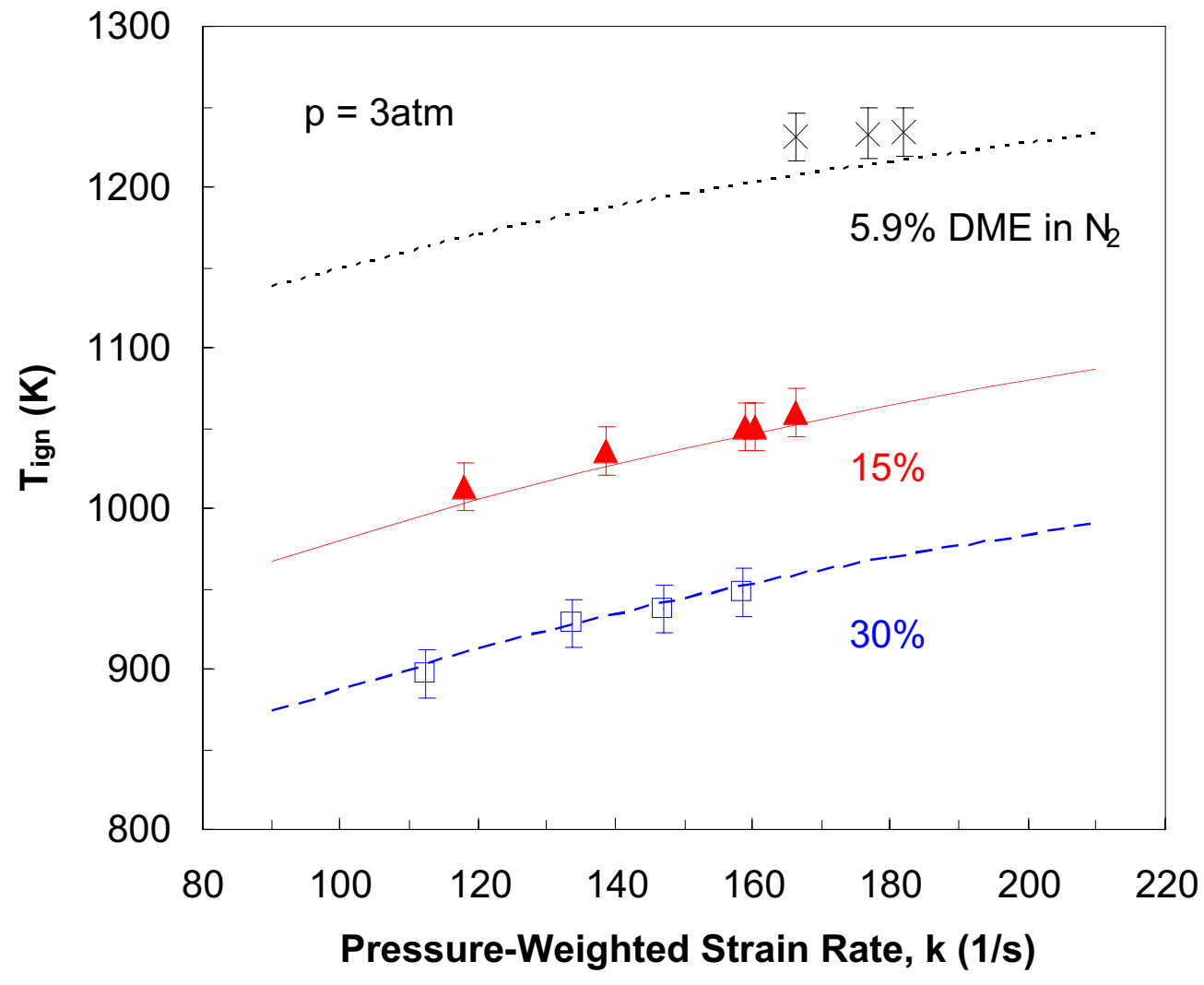

Figure 4 


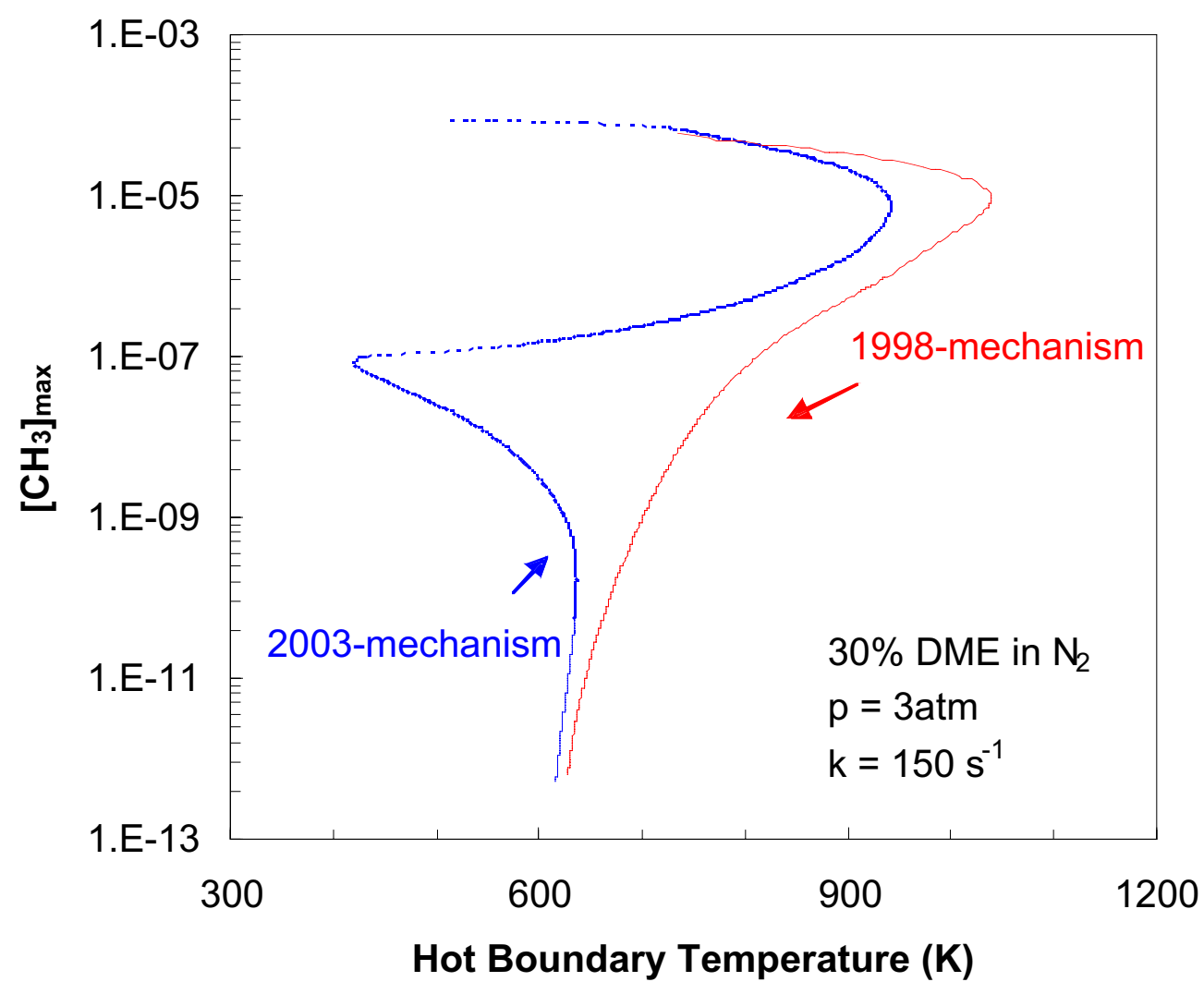

Figure 5 

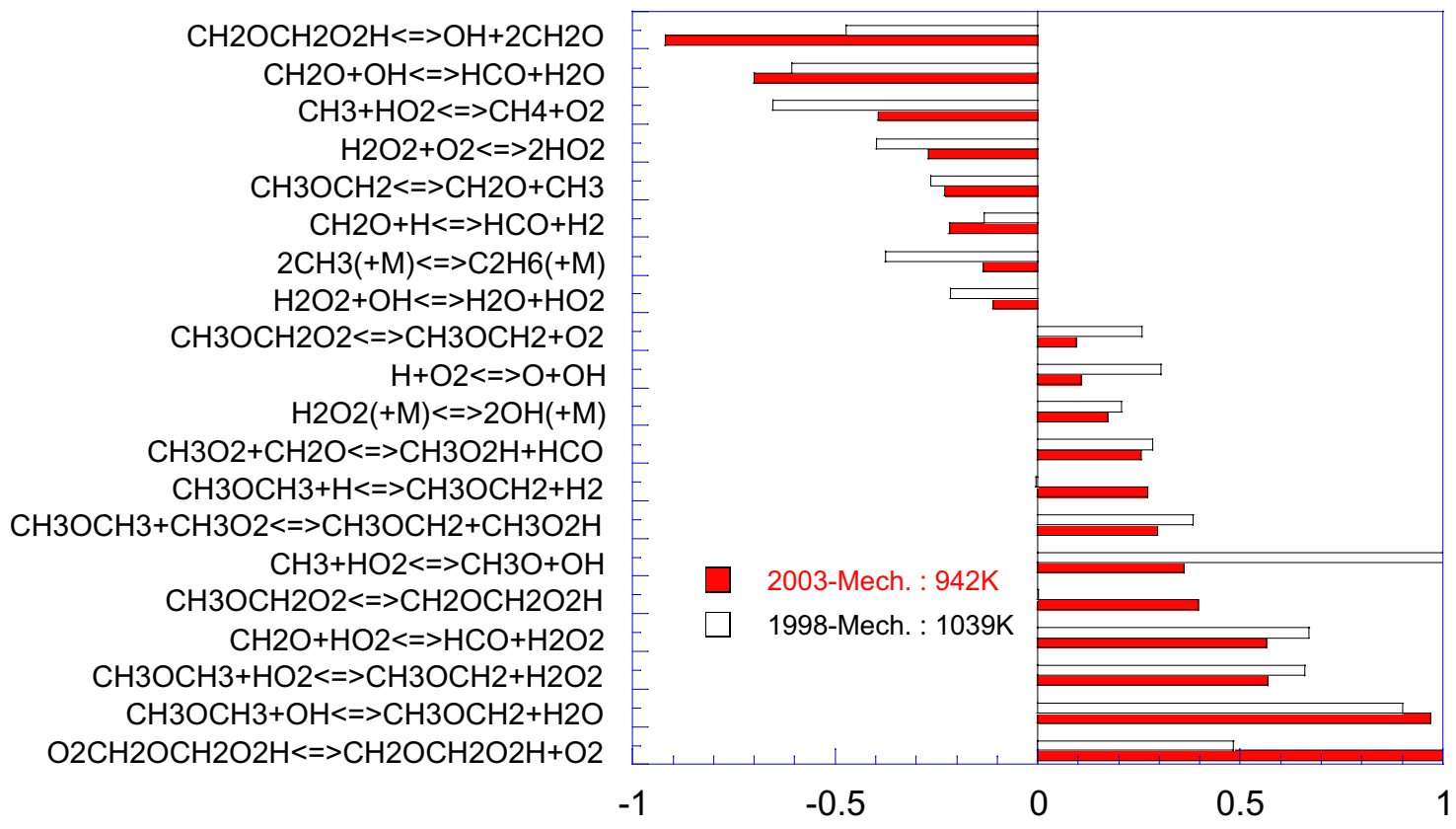

Figure 6 


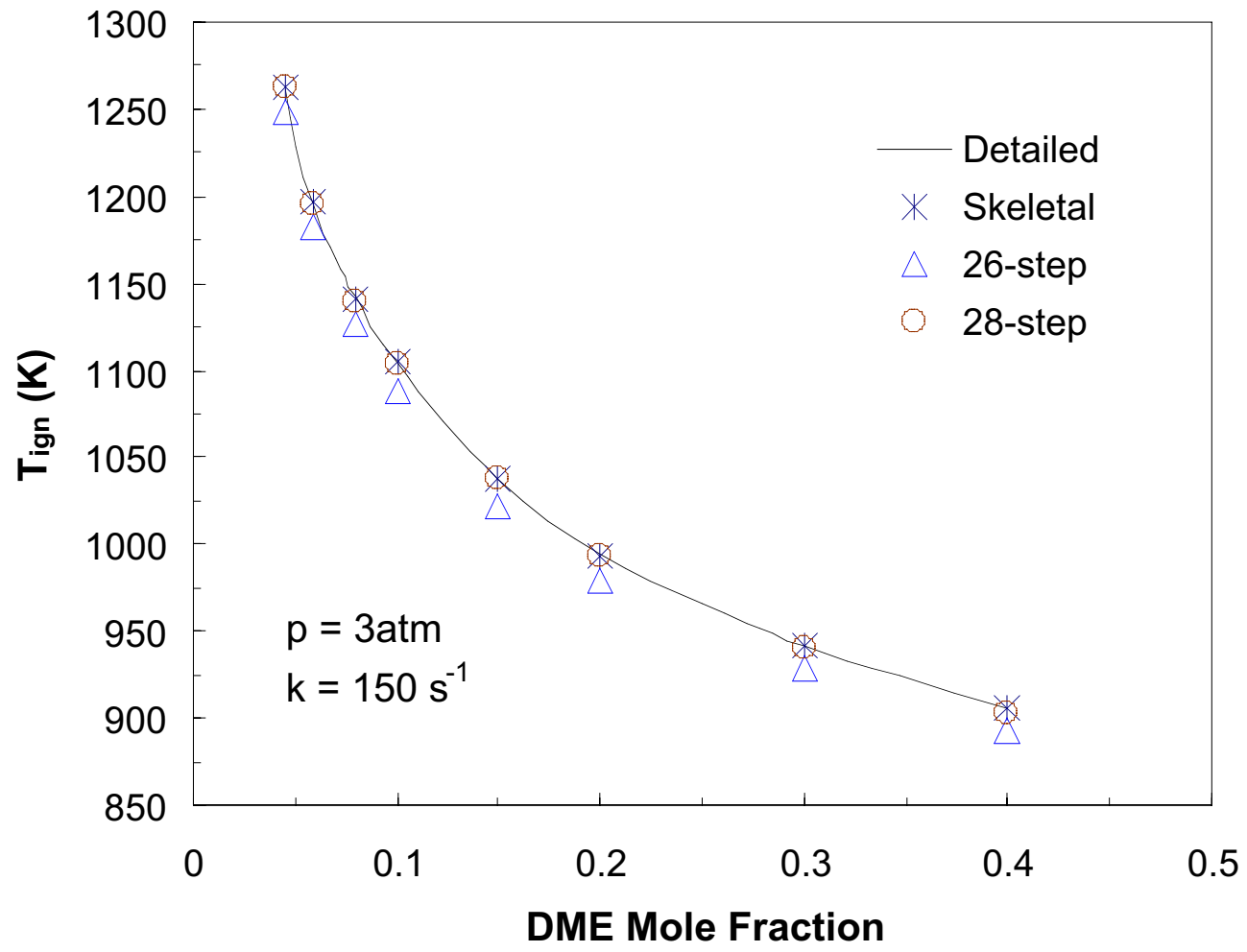

Figure 7 